\title{
Coronary Artery Bypass Surgery or Interventional Cardiology? Why not both? Let's go for Hybrid Coronary Revascularization
}

\section{Khalida Soomro*}

Consultant Cardiologist, Department of Cardiology, Ziauddin University Hospital Karachi, Pakistan

\author{
Corresponding author \\ Khalida Soomro, Consultant Cardiologist, Department of Cardiology, \\ Ziauddin University Hospital Karachi, Pakistan, E-mail: prokhalidasoomro@ \\ hotmail.com
}

Submitted: 01 Jan 2020; Accepted: 07 Jan 2020; Published: 20 Jan 2020

\begin{abstract}
The options for coronary artery disease have greatly expanded during the course of the last two and half decades with the advent of hybrid technology in the 1990s. The hybrid option for treating cardiac disease implies using the technology of both interventional cardiology and cardiac surgery to offer the patients the best available treatments for coronary artery disease while minimizing the risks of the surgery, example can be a patient with a partial blockage in one coronary artery and a complete blockage in another. In this case, a combination revascularization approach might work best to restore blood flow to the heart muscle. An interventional cardiologist inserts a stent into one coronary artery to open it up, and then a surgeon grafts a bypass vessel to let blood flow around the other blockage. Hybrid Cardiac Surgery a collaborative approach reduces risk of complication, shorten recovery times and improve outcomes This fragmented approach to care is starting to change to a much-needed innovation in hospital design by set up including all the equipment needed for diagnostic imaging, minimally invasive procedures, and traditional surgery, the key requirement is productive collaboration of heart team comprising heart surgeons, interventional cardiologists, and other specialists by working together in the same space, at the same time. Although indications and patient selection of these procedures are still to be defined but high-risk patients have already been shown to benefit from hybrid approaches, In conclusion, HCR is can be used to treat multi-vessel CAD with favourable early results, though growth in the field is limited by surgical experience and success with minimally invasive techniques, should be performed in high volume centers.
\end{abstract}

Keywords: Coronary Artery Bypass Graft Surgery, Hybrid Coronary Artery Revascularization, Minimally Invasive Direct Coronary artery Bypass Grafting, Percutaneous Coronary Intervention

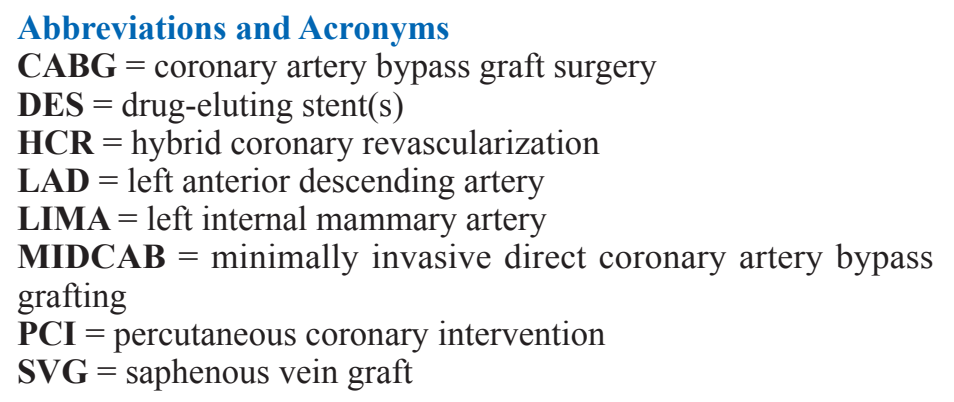

\section{Introduction}

Hybrid coronary revascularizations is an evolving technique that is being used as an alternative to traditional median sternotomy coronary artery bypass graft surgery it combines a minimally invasive approach to bypass the left anterior descending coronary artery with left internal mammary artery and percutaneous coronary intervention to re-vascularize the other coronary arteries in the treatment of multi-vessel coronary artery disease in patients appropriate for this technique from low-risk patients with low SYNTAX lesions outside the left anterior descending artery (LAD), to high-risk patients with multiple comorbidities who are felt by the heart team to benefit most by avoiding a sternotomy during the same hospital stay, especially in patients with complex LAD lesions that may not be ideal for stenting along with lesions in other coronary arteries that are easily stented, These Patients can benefit from the longevity of the left internal mammary artery anastomosed to the LAD (LIMA-LAD) using direct visualization methods, such as a thoracotomy or partial sternotomy [1-9].

Hybrid Coronary Re-vascularization

It was first introduced in the mid-1990s as a pioneering treatment approach with the thought to bring together the "best of both worlds" of cardiology and cardiac surgery by attempting to achieve the maximum effect of revascularization in the least invasive way possible.

HCR consists of two procedures, and the timing of these is dependent upon several factors. In general, it is best to treat the culprit lesion first most commonly in clinical practice [3,6-8]. 


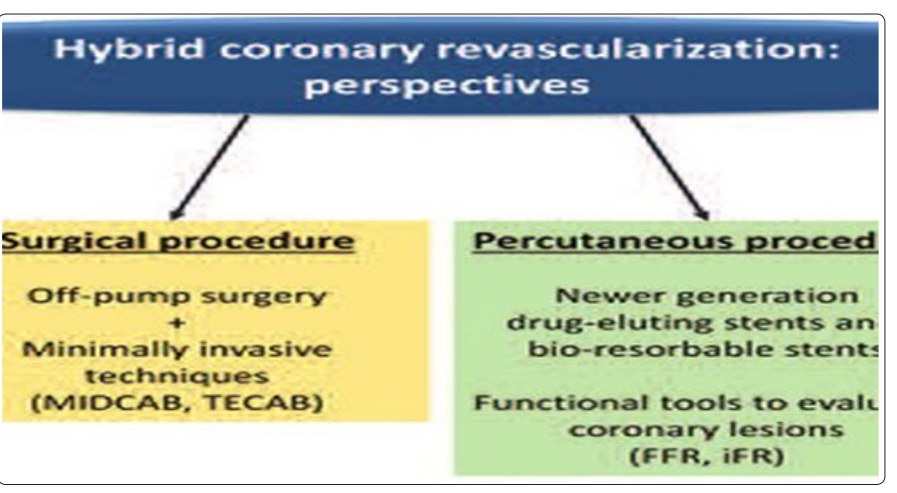

Percutaneous interventions in hybrid procedures include implantation of stents. aims to reduce surgical trauma minimizing adverse cardiovascular events while preserving long term survival benefits and excellent patency rates associated with the durable left internal mammary artery graft to the left anterior descending artery and with the good patency rates of drug-eluting stents then saphenous vein grafts to non-left anterior descending vessels. Robotic technology such as the daVinci surgical tele manipulation system is increasingly used [10-13].
The objective of this review is to discuss HCR's benefits, the current evidence behind it, its limitations and procedural challenges and purpose is to rationalize the appropriateness of HCR in being included in the complicated coronary artery disease treatments and collaboration between cardiac surgeons and interventional cardiologists for ideal outcomes.

In theory this is a very attractive revascularization strategy, and has been gaining ground lately due to advances in technology and techniques, an increasing acceptance of the 'heart team' approach and its popularity among patients and care teams. Still much of HCR remains controversial - by definition, with regard to timing, techniques, equipment, patient selection criteria, and the implementing team's learning curve [14,15]. Although Several studies have shown that HCR (LIMA-LAD performed either conventionally or minimally invasively, plus PCI to nonLAD vessels) provides better short-term outcomes with regard to decreased ventilation and ICU time, reduced requirement for blood transfusion, and shortened hospital stay. But there has been no strong evidence on improved mortality, and late comparative outcomes are still insufficient and raising concerns regarding $\mathrm{HCR}$, s role and generalizability [16-18].

Table 1: Literature Review

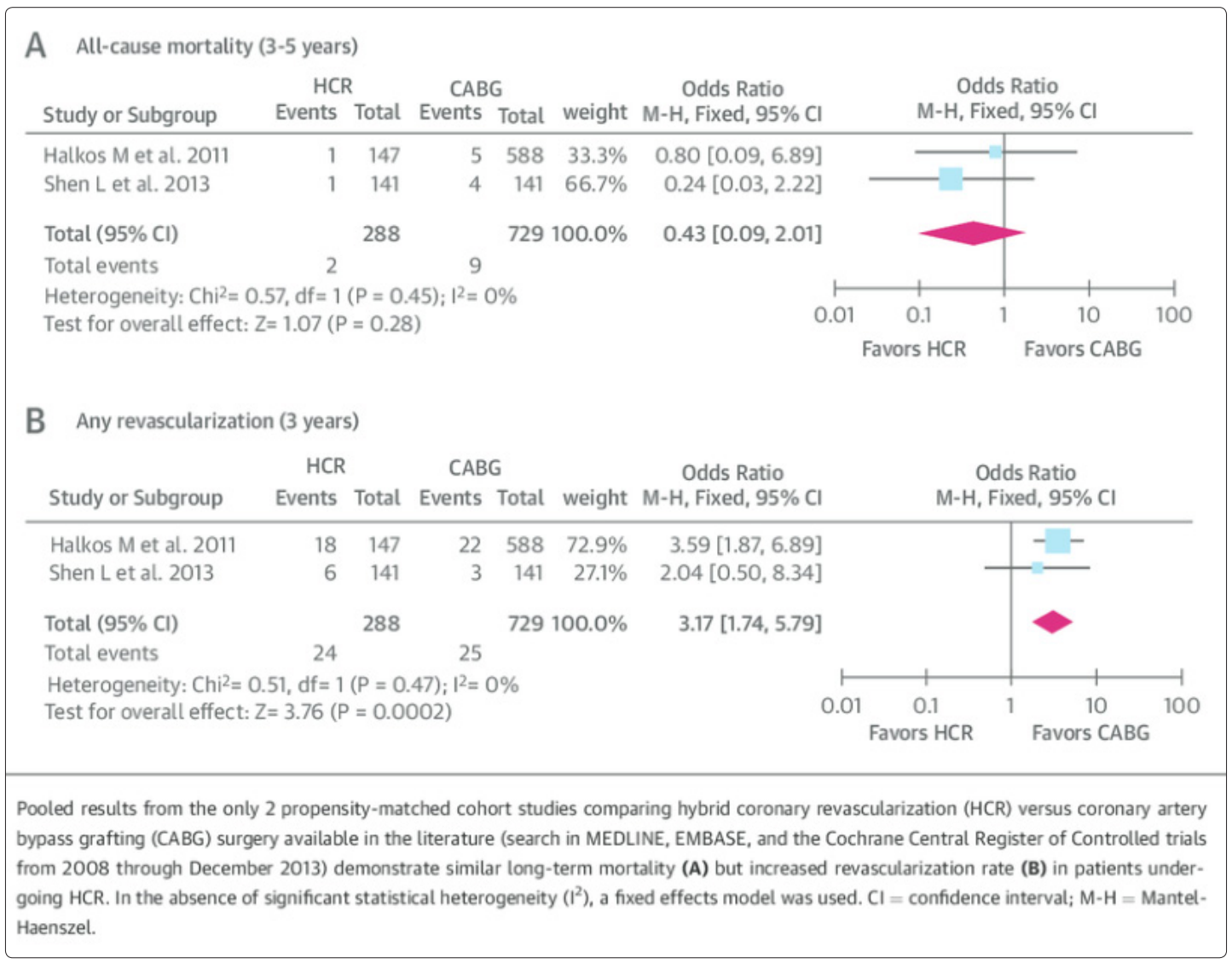


Table 2: Literature Review

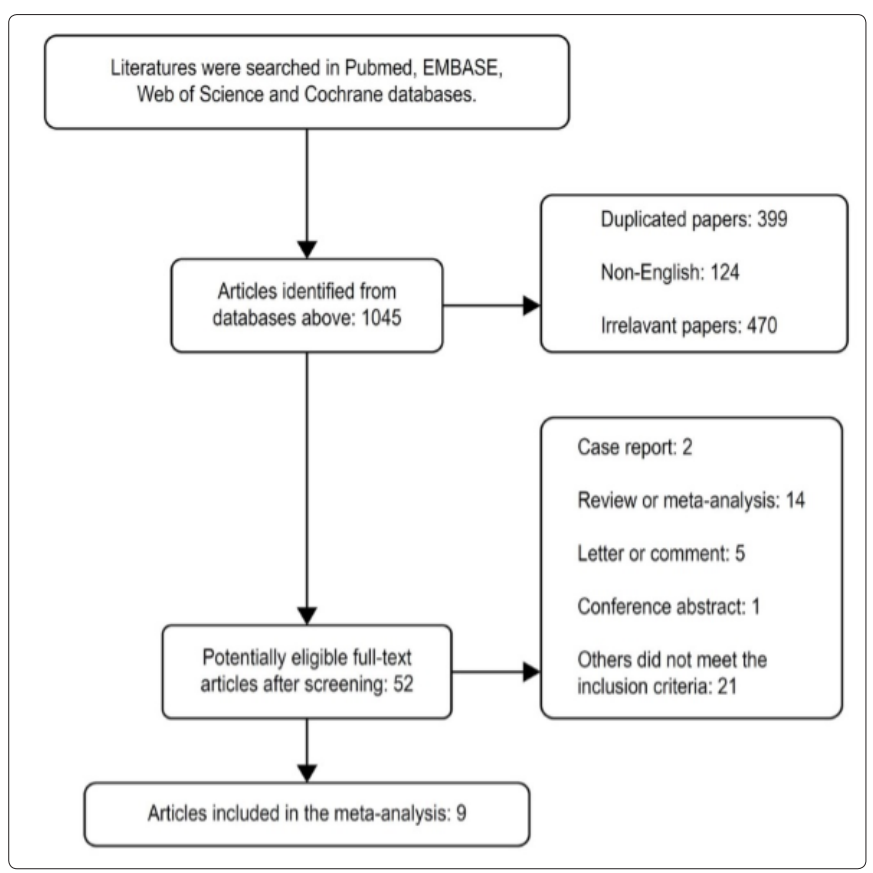

The Risk and benefits of completing the revascularization with PCI with stenting vis CABG

Generally Open multi-vessel bypass surgery is highly invasive but very effective in the long term; the hybrid coronary revascularization is less invasive with less surgical trauma minimizing adverse cardiovascular events, preserving long term survival benefits by excellent patency rates associated with the durable left internal mammary artery graft to the left anterior descending artery, the LIMA powerfully resists thrombosis and atherosclerosis ((9)and use of the drug eluting stents in other arteries than venous [9]. Shows more repeat revascularization procedures yet [19]. Vein graft patency versus stent restenosis and thrombosis is important here unlike arterial conduits, veins are not designed to bear the load of systemic pressure; hence, venous grafts are more prone to atherosclerotic degeneration and progressive narrowing with high early and long-term failure rates. Where as the LIMA -LAD graft is associated with long term patency rates reaching at 10 years $(10,110$ hence protects the native coronary tree from the deleterious effects of disease progression (9). In the ex vivo PREVENT IV (Vein graft Engineering via Transfection IV) study (12), angiographic midterm (1 to 1.5 years) saphenous vein graft (SVG) failure, defined as stenosis $\geq 75 \%$, stood as high as $46 \%$, whereas reported graft occlusion rates in the literature range from $6.2 \%$ to $32 \%$ at 1 year (averaging $20 \%$ ) 13, 14, 15, 16, 17, 29\% at 10 years, and $68 \%$ at 15 years (10) post-coronary artery bypass graft surgery $(\mathrm{CABG})[20,21]$. As well as with the good patency rates of drug-eluting stents due to lower stent restenosis and thrombosis leads to lower occlusion ratesrespectively Newer drug-eluting stent (DES) platforms with (e.g., everolimus-eluting stents [EES] or zotarolimuseluting stents [ZES]) or without (bio absorbable polymer-based or polymer-free stents) durable polymers show favourable outcomes, with 1-year target lesion revascularization (TLR) rates as low as 3\% to $3.25 \%$. Even in high-risk patients and complex lesions, ZES and EES maintain very low 1 -year TLR rates of $4.4 \%$ and $4 \%$, respectively [22-24].

Therefore PCI with stenting provide strong competition for SVG revascularization because, unlike an LIMA-LAD graft, early disease progression occurs in the proximal native coronary segment alongside SVG deterioration [25]. And significant angiographic SVG stenosis occurs at least twice as frequently then stent restenosis using the latest technology platforms. Saphenous vein patency is $85 \%$ at 6 months, $71-93.8 \%$ at 1 year and $74-81 \%$ at 5 years [26-28].This high SVG failure rate is shown in the results from the PREVENT IV trial [6]. How ever ischemia-driven revascularization rates are found considerably higher in stented patients with treated multivessel CAD [29]. Further more due to stent thrombosis the clinical consequences are more dramatic and frequently associated with major adverse clinical events (MACE) [30]. A strong argument for surgical bypass grafts is that most native disease progression occurs in the proximal coronary segment. thereby preserving blood flow distally $[30,23,24]$. But disease can progress at or near stents, with recurrence of ischemia.

\section{Indications}

Which patients are suitable for $\mathrm{HCR}$

HCR appears appealing for the subset of patients with the a fore mentioned coronary anatomy and others considered too high risk for open cardiopulmonary bypass surgery via midline sternotomy especially those with a high risk of deep sternal wound infection e.g., diabetics, morbidly obese, severely impaired left ventricular function, chronic kidney disease, significant carotid or neurological disease, severe aortic calcification, prior sternotomy, and lack of venous conduits [31].

The decision of heart team for selection of appropriate patient for HCR should be based on an important anatomical feature that is plaque burden in the proximal LAD well characterized by the SYNTAX (Synergy Between PCI With TAXUS and Cardiac Surgery) score [1]. The classic indication for HCR in multi-vessel CAD includes: [31,32]

1. A proximal complex LAD lesion with optimal distal anatomy amenable to LIMA-to-LAD grafting;

2. Non-LAD lesions amenable to PCI, in a patient with no contraindications to dual antiplatelet therapy (DAPT).

3. A high likelihood of achieving "reasonable incomplete revascularization" with such an approach.

4. Complex distal left main lesions are also ideal for HCR if the circumflex artery territory is involved

5. Based on current literature, an algorithm is an aid in the decision-making with regard $\mathrm{HCR}$ and $\mathrm{CABG}$ 


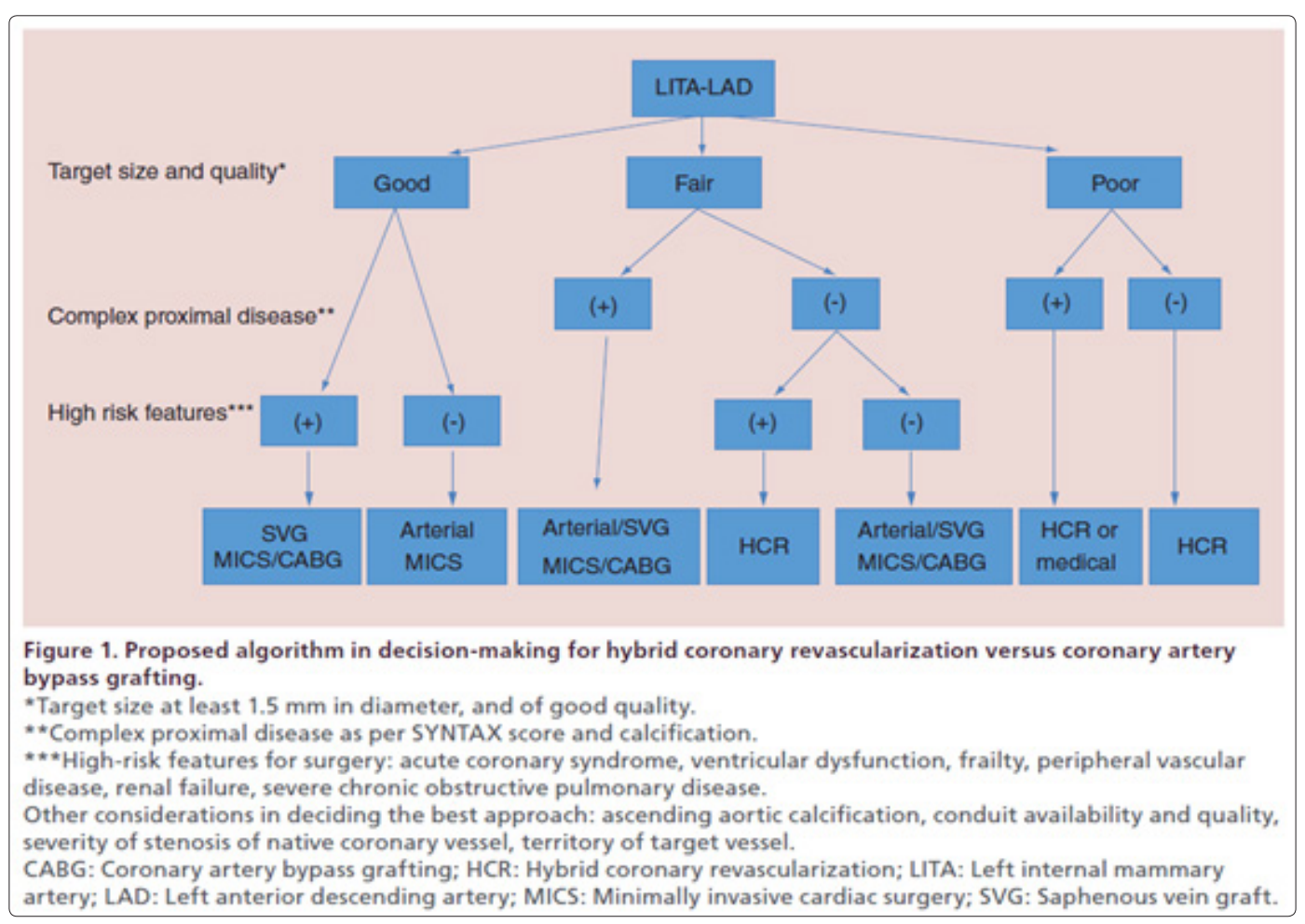

Let's go for hybrid coronary vascularization?

\section{What Guidelines Says}

American guidelines in 2011 recommendations for HCR indicate that "Hybrid coronary revascularization is reasonable in patients with 1 or more of the following: limitations to traditional CABG, such as heavily calcified proximal aorta or poor target vessels for CABG (but amenable to PCI); lack of suitable graft conduits; unfavourable LAD artery for PCI (i.e. excessive vessel tortuosity or chronic total occlusion)" (Class IIa, Level of evidence B), and "Hybrid coronary revascularization may be reasonable as an alternative to multi-vessel $\mathrm{PCI}$ or $\mathrm{CABG}$ in an attempt to improve the overall risk-benefit ratio of the procedures" (Class IIb, Level of evidence C). On the other hand, Hybrid procedure, defined as consecutive or combined surgical and interventional revascularization may be considered in specific patient subsets at experienced centres (Class IIb, Level of evidence B), according to European guidelines in 2014 supported by European Society of Cardiology/ European Association for Cardiothoracic Surgery included HCR for Myocardial Revascularization gave it a Class IIb in patient subsets at experienced centres $[33,34]$.

\section{Acceptance of Hybrid coronary vascularization}

The lack of several large randomized controlled trials (RCTs) involving different risk groups, hinders the identification of an HCR target group. Consequently, physicians and surgeons do not embrace HCR in routine clinical practice. In a study from the Society of Thoracic Surgeons (STS) Adult Cardiac Surgery Database, HCR represented just $0.48 \%(\mathrm{n}=950$ patients) of the total $\mathrm{CABG}$ volume $(\mathrm{n}=198,622)$ between July 2011 and March 2013. Difficulty in performing the procedure may be the reason.

\section{Discussion}

HCR has been practiced since 2 decades and more commonly as unplanned approaches to either salvage CABG or salvage PCI.
The first series of planned HCR were attempts to provide adequate revascularization for high-risk patients published in 1996, yielded acceptable results. Later further literature on subject come out about its efficacy, it is now included in several revascularization guidelines. With the growing acceptance of HCR in the medical community as well as in addition to an increasing demand from patients for less invasive therapies and minor splitting of the sternum which is very valid concern physically and psychologically minimally invasive surgery is now flourishing with sternal-sparing approaches now HCR can easily be incorporated with mini-thoracotomies direct approach, to endoscopic, to totally endoscopic robot-assisted surgeries. A mentality shift has been noted among healthcare practitioners toward expanding the indications of HCR, from initially allocating it only to high-risk patients due to excellent short-term outcomes irrespective of whether a MIDCAB or robotic approach is used [10-13]. The international literature shows that HCR can be technically accomplished with low 30-day and long-term mortality rates $(0-2.6 \%$ and $84.8-100 \%$ respectively).LIMA patency is reported to be over $92 \%$. The eventfree survival rate is between $70 \%$ and $100 \%$, whereas the incidence of MACCE ranges from $0 \%$ to $12.2 \%$ and blood transfusion rates vary from $0 \%$ to $35.4 \%$. In HCR the benefit of LIMA-LAD reliably with patency rate greater than $85 \%$ and less hospital stay due to less frequent post-operative complications then conventional CABG was found in observational data, At mid-term follow-up, HCR seems to have better rates of revascularization than PCI but may not be identical to conventional CABG $[2,29,33,35]$. Patient satisfaction is extremely high with HCR, and patients are back at work with no activity limitations much faster than after a sternotomy.

The best timings for HCR in one stage or as a two-stage procedure is still doubted. However, a one-stage HCR procedure in a hybridoperating room is advantageous compared to staged HCR with complete revascularization with minimal patient discomfort.

When PCI is performed first, antiplatelet agents must be continued 
during surgery, which can be associated with higher chest tube output. Performing surgery first provides protection of the completed LIMA-LAD anastomosis. When performed concurrently in a hybrid operation room, immediate assessment of the anastomosis can be performed. In a two-stage procedure, patients are incompletely revascularized between the procedures, so there is a significant risk for cardiovascular events. Performing PCI of non-LAD lesions first is currently limited to patients with acute coronary syndrome due to non-LAD lesions.

A major weakness of data on HCR is the lack of robust randomized data comparing the approach to conventional surgery and PCI $[14,15,33]$. Much more long-term data is needed before any firm conclusions can be made [36]. A major limitation to the expansion of HCR is the lack of surgeons committed due to difficulty in performing these procedures $[14,15]$. MIDCAB is more technically challenging than conventional CABG. The use of robotics to improve visualization and instrument precision may be associated with a lower learning curve [10-13]. The TECAB approach requires more time to learn, Here Beyond the surgical learning curve, another key component for HCR is to build a team with key stakeholders actively involved. This involves not just the surgical team, (i.e., anaesthesiologist, first assistant, surgical technician, and circulator nurse) but also referring cardiologists and interventionists. Until the learning curve is complete [10-13]. There is a need for intense training in minimally invasive cardiac surgery (MICS), for availability of radiologic, interventional and surgical equipment, and of course, for a heart team with a cooperative frame of mind and a willingness to fit a common time among themselves. Access to a robot may need to be worked out ahead of time.

Table 3: Literature Review

Hybrid Coronary revascularization and Complications

\begin{tabular}{|c|c|c|c|c|}
\hline & $\begin{array}{l}\text { TECAB } \\
\text { prior to } \mathrm{PCl} \\
(n=61)\end{array}$ & $\begin{array}{l}\text { PCI prior } \\
\text { to TECAB } \\
(n=6)\end{array}$ & $\begin{array}{l}\text { Simultaneous } \\
\text { hybrid } \\
(n=23)\end{array}$ & $P$-value \\
\hline Perioperative death & $\mathrm{O}(\mathrm{O} \%)$ & $\mathrm{O}(0 \%)$ & $\mathrm{O}(\mathrm{O} \%)$ & n.a. \\
\hline Surgical difficulties & $17(27.9 \%)$ & $3(50 \%)$ & $7(30.4 \%)$ & 0.528 \\
\hline Conversion & $2(3.3 \%)$ & $2(33.3 \%)$ & $0(0 \%)$ & 0.001 \\
\hline $\begin{array}{l}\text { Rethoracotomy for } \\
\text { bleeding }\end{array}$ & $0(0 \%)$ & $1(16.7 \%)$ & $1(4.3 \%)$ & 0.022 \\
\hline Undesired event & $6(9.8 \%)$ & $3(50 \%)$ & $1(4.3 \%)$ & 0.023 \\
\hline Vascular complication & $1(1.6 \%)$ & $0(0 \%)$ & $0(0 \%)$ & 0.786 \\
\hline Leg ischaemia & $0(0 \%)$ & $0(0 \%)$ & $0(0 \%)$ & n.a. \\
\hline Myocardial infarction & $1(1.6 \%)$ & $0(0 \%)$ & $\mathrm{O}(\mathrm{O} \%)$ & 0.961 \\
\hline Atrial fibrillation & $12(19.7 \%)$ & $1(16.7 \%)$ & $3(13 \%)$ & 0.534 \\
\hline Stroke & $\mathrm{O}(0 \%)$ & $\mathrm{O}(\mathrm{O} \%)$ & $\mathrm{O}(0 \%)$ & n.a. \\
\hline $\begin{array}{l}\text { Renal failure requiring } \\
\mathrm{HF}\end{array}$ & $0(0 \%)$ & $\mathrm{O}(\mathrm{O} \%)$ & $\mathrm{O}(0 \%)$ & n.a. \\
\hline Respiratory failure & $3(4.9 \%)$ & $\mathrm{O}(0 \%)$ & $\mathrm{O}(\mathrm{O} \%)$ & 0.478 \\
\hline Wund complications & $1(1.6 \%)$ & $0(0 \%)$ & $\mathrm{O}(\mathrm{O} \%)$ & 0.410 \\
\hline
\end{tabular}

\section{Conclusion}

Coronary artery bypass grafting in all its forms remains the first choice in coronary revascularization and hybrid coronary revascularization is a good alternative in high-risk patients $[2,19]$. If HCR is to be accepted as a first-line approach for multi-vessel disease, it should be measured against the current gold standard in the treatment of multi-vessel CAD, which is CABG. It is uncontested that the most valuable revascularization in CABG is the LIMA-LAD graft. There is now improved understanding of the specificities of graft conduits that enable surgeons and interventional cardiologists provide excellent outcomes. The controversy lies on the selection of the next best approach.

\section{References}

1. Taggart DP (2011) Lessons learned from the SYNTAX trial for multivessel and left main stem coronary artery disease. Curr Opin Cardiol 26: 502-507.

2. Hulusi M, Basaran M, Yilmaz M, Yaymaci B, Ulusoy E, et al. (2006) Hybrid coronary revascularization in high risk patients. Texas Heart Inst J 33: 458-462.

3. Cisowski M, Morawski W, Drzewiecki J, Kruczak W, Toczek $\mathrm{K}$, et al. (2002) Integrated minimally invasive direct coronary artery bypass grafting and angioplasty for coronary artery revascularization. Eur J Cardiothorac Surg 22: 261-265.

4. Del Giglio M, Dell'Amore A, Zuffi A, Sokoli A (2009) Onestage hybrid procedure: association between awake minimally invasive surgical revascularization and percutaneous coronary intervention. Interact Cardiovasc Thorac Surg 9: 551-553.

5. Gilard M, Bezon E, Cornily JC, Mansourati J, Mondine P, et al. (2007) Same-day combined percutaneous coronary intervention and coronary artery surgery. Cardiology 108: 363-367.

6. Gąsior M, Zembala MO, Tajstra M, Filipiak K, Gierlotka M et al. (2014) Hybrid revascularization for multivessel coronary artery disease. J Am Coll Cardiol Intv 7: 1277-1283.

7. Ralf E Harskamp, Brennan JM, Ying Xian, Michael E Halkos, John D Puskas, et al. (2014) Practice patterns and clinical outcomes after hybrid coronary revascularization in the United States. Circulation 130: 872-879.

8. DelGiglio M, Dell'Amore A, Zuffi A, Sokoli A (2009) Onestage hybrid procedure: association between awake minimally invasive surgical revascularization and percutaneous coronary intervention. Interact CardioVasc Thorac Surg 9: 551-553.

9. Fitzgibbon GM, Kafka HP, Leach AJ, Keon WJ, Hooper GD, et al. (1996) Coronary bypass graft fate and patient outcome: angiographic follow-up of 5,065 grafts related to survival and reoperation in 1,388 patients during 25 years. J Am Coll Cardiol 28: 616-626.

10. Farhat F, Depuydt F, Praet FV, Coddens J, Vanermen H (2000) Hybrid cardiac revascularization using a totally closed-chest robotic technology and a percutaneous transluminal coronary dilatation. Heart Surg Forum 3: 119-120.

11. Jansens JL, DeCroly P, De Canniere D (2009) Robotic hybrid procedure and triple-vessel disease. J Card Surg 24: 449-450.

12. Davidavicius G, Van Praet F, Mansour S, Casselman F, Bartunek J, et al. (2005) Hybrid revascularization strategy: a pilot study on the association of robotically enhanced minimally invasive direct coronary artery bypass surgery and fractional flowreserve-guided percutaneous coronary intervention. Circulation 112: I317-I322.

13. Stahl KD, Boyd WD, Vassiliades TA, Karamanoukian HL (2002) Hybrid robotic coronary artery surgery and angioplasty in multivessel coronary artery disease. Ann Thorac Surg 74: S1358-S1362.

14. Leacche M, Zhao DX, Umakanthan R, Byrne JG (2012) Do hybrid procedures have proven clinical utility and are they the wave of the future? Hybrid procedures have no proven clinical utility and are not the wave of the future. Circulation 125: 2504-2510.

15. Shannon J, Colombo A, Alfieri O (2012) Do hybrid procedures have proven clinical utility and are they the wave of the future? Hybrid procedures have proven clinical utility and are the wave of the future. Circulation 125: 2492-2503.

16. Friedrich GJ, Bonatti J, Dapunt OE (1997) Preliminary experience with minimally invasive coronary-artery bypass 
surgery combined with coronary angioplasty. N Engl J Med 336: 1454-1455.

17. Isomura T, Suma H, Horii T, Sato T, Kobashi T, et al. (2000) Minimally invasive coronary artery revascularization: off-pump bypass grafting and the hybrid procedure. Ann Thorac Surg 70: 2017-2022.

18. Riess FC, Schofer J, Kremer P, Riess AG, Bergmann H, et al. (1998) Beating heart operations including hybrid revascularization: initial experiences. Ann Thorac Surg 66: 1076-1081.

19. Riess FC, Bader R, Kremer P, Kuhn C, Kormann J, et al. (2002) Coronary hybrid revascularization from January 1997 to January 2001: a clinical follow-up. Ann Thorac Surg 73:1849-1855.

20. Dai Une, Alexander Kulik, Pierre Voisine, Michel Le May, Marc Ruel (2013) Correlates of saphenous vein graft hyperplasia and occlusion 1 year after coronary artery bypass grafting: analysis from the CASCADE randomized trial. Circulation 128: S213-S218.

21. Farooq V, Serruys PW, Zhang Y, Mack M, Ståhle E, et al. (2013) Short-term and long-term clinical impact of stent thrombosis and graft occlusion in the SYNTAX trial at 5 years: Synergy Between Percutaneous Coronary Intervention with Taxus and Cardiac Surgery trial. J Am Coll Cardiol 62: 2360-2369.

22. Sarno G, Lagerqvist B, Fröbert O, Nilsson J, Olivecrona G, et al. (2012) Lower risk of stent thrombosis and restenosis with unrestricted use of 'new-generation' drug-eluting stents: a report from the nationwide Swedish Coronary Angiography and Angioplasty Registry (SCAAR). Eur Heart J 33: 606-613.

23. Serruys PW, Ong AT, van Herwerden LA, Sousa JE, Jatene A, et al. (2005) Five-year outcomes after coronary stenting versus bypass surgery for the treatment of multivessel disease: the final analysis of the Arterial Revascularization Therapies Study (ARTS) randomized trial. J Am Coll Cardiol 46: 575-581.

24. Serruys PW, Morice M, Kappetein AP, Colombo A, Holmes DR, et al. (2009) Percutaneous coronary intervention versus coronary-artery bypass grafting for severe coronary artery disease. N Engl J Med 360: 961-972.

25. Alexander JH, Hafley G, Harrington RA, Peterson ED, Ferguson TB, et al. (2005) Efficacy and safety of Edifoligide, an E2F transcription factor decoy, for prevention of vein graft failure following coronary artery bypass graft surgery. PREVENT IV: a randomized controlled trial. JAMA 294: 2446-2454.

26. Ruel M, Shariff MA, Lapierre H, Goyal N, Dennie C, et al. (2014) Results of the minimally invasive coronary artery bypass grafting angiographic patency study. J Thorac Cardiovasc Surg 147: 203-208.

27. Wittwer T, Haverich A, Cremer JT, Boonstra PW (2000) The hybrid procedure for myocardial revascularization: intermediate results. Ann Thorac Surg 69: 975.

28. Riess FC, Bader R, Kremer P, Kühn C, Kormann J, et al. (2002) Coronary hybrid revascularization from January 1997 to January 2001: a clinical follow-up. Ann Thorac Surg 73: 1849-1855.

29. De Canniere D, Jansens JL, Goldschmidt- Clermont P, Barvais L, Decroly P, et al. (2001) Combination of minimally invasive coronary bypass and percutaneous transluminal coronary angioplasty in the treatment of double-vessel coronary disease: Two-year follow-up of a new hybrid procedure compared with 'on-pump' double bypass grafting. Am Heart J 142: 563-570.

30. Bonatti J, Schachner T, Bonaros N, Jonetzko P, Ohlinger A, et al. (2008) Simultaneous hybrid coronary revascularization using totally endoscopic left internal mammary artery bypass grafting and placement of rapamycin eluting stents in the same interventional session. The COMBINATION pilot study. Cardiology 110: 92-95.

31. Presbitero P, Nicolini F, Maiello L, Franciosi G, Carcagni A, et al. (2001) "Hybrid" percutaneous and surgical coronary revascularization: selection criteria from a single-center experience. Ital Heart J 2: 363-368.

32. Bonatti J, Lehr E, Vesely MR, Friedrich G, Bonaros N, et al. (2010) Hybrid Coronary Revascularization : Which patients, when, how. Curr Opin Cardiol 25: 568-574.

33. Reicher B, Poston RS, Mehra MR, Joshi A, Odonkor P, et al. (2008) Simultaneous "hybrid" percutaneous coronary intervention and minimally invasive surgical bypass grafting: feasibility, safety, and clinical outcomes. Am Heart J 155: 661667.

34. Stephan Windecker, Philippe Kolh, Fernando Alfonso, JeanPhilippe Collet, Jochen Cremer, et al. (2014) 2014 ESC/EACTS Guidelines on myocardial revascularization: The Task Force on Myocardial Revascularization of the European Society of Cardiology (ESC) and the European Association for CardioThoracic Surgery (EACTS) Developed with the special contribution of the European Association of Percutaneous Cardiovascular Interventions (EAPCI). Eur Heart J 35: 25412619.

35. Jones ML, Qiu S, Sudarshan C (2010) Perioperative outcomes in hybrid versus conventional surgical coronary artery revascularisation. Interact Cardiovasc Thorac Surg 11: 292-296.

36. Holzhey DM, Jacobs S, Walther T, Mochalski M, Mohr FW, et al. (2007) Cumulative sum failure analysis for eight surgeons performing minimally invasive direct coronary artery bypass. J Thorac Cardiovasc Surg 134: 663-669.

Copyright: (C2020 Khalida Soomro. This is an open-access article distributed under the terms of the Creative Commons Attribution License, which permits unrestricted use, distribution, and reproduction in any medium, provided the original author and source are credited. 